LETTER TO THE EDITOR

\title{
Depressed ventilatory drive for respiratory muscle weakness and chemo-responsiveness as a pathophysiological mechanism of CSA after surgery for obstructive sleep apnoea
}

\author{
Apnea notturna centrale da transitoria depressione ventilatoria polmonare e risposta \\ chemo-recettoriale periferica causata da debolezza dei muscoli respiratori \\ nei pazienti operati per l'apnea ostruttiva del sonno \\ Domenico Maurizio Toraldo ${ }^{1}$, Michele Arigliani², Michele De Benedetto ${ }^{3}$ \\ Department of Rehabilitation "V. Fazzi" Hospital, Cardio-Respiratory Unit Care, ASL/Lecce, San Cesario di Lecce, Lecce, Italy; \\ ${ }^{2}$ ENT Unit, Vito Fazzi Hospital, ASL Lecce, Italy; ${ }^{3}$ ENT Unit, Vito Fazzi Hospital, ASL Lecce, Italy
}

KEY WORDS: central sleep apnoea, complex sleep apnoea, loop gain

PAROLE CHIAVE: apnea notturna centrale, apnea notturna complessa, ciclo di guadagno

This Letter is in reply to the Case Series and Reports published in Acta Otorhinolaryngologica Italica 2018;38:476-479. Some reflections on the description of the clinical case presented in the paper entitled "Treatment-emergent central sleep apnoea after surgery for obstructive sleep apnoea” are reported by E. Testani, E. De Corso, A. Losurdo, A. Fiorita, C. Vollono, G. Della Marca, E. Scarano. The description offers some insights into the pathophysiological aspects of OSA (Obstructive Sleep Apnoea) patients during the postsurgical phase: the Loop gain mechanism and the interpretation of complex apneoas in the post-surgery phase and the relative hypotheses of possible therapeutic solutions.

Dear Editor,

In order to avoid any possible misunderstandings, we would first like to point out that the case of CSA (Central Sleep Apnoea), resulting from the OSA surgery described, cannot be considered a complication of OSA surgery and may occur as a temporary resetting of the respiratory system. CSA can also occur in 5\% of patients affected by OSA during CPAP treatment: this phenomenon is called complex sleep apnoea and occurs when the air flow generated by the CPAP device restores patency of the pharyngeal airways ${ }^{1}$. CSA is defined by the absence of air flow accompanied by cessation of ventilation during sleep. In most forms, CSA manifests cyclically and alternately. It can have cyclic and/or periodic forms characterised by a regular oscillating ventilatory movement: a phase of respiratory hypoventilation, characterised by breathing cessation, is followed in turn, as compensation, by a hyperventilation phase or apnoea phenomena. It can also have other more irregular forms ${ }^{2}$. CSA is of clinical interest because it causes arterial desaturation of oxygen and hypoxaemia, hypercapnia, post-apneic arousal, nocturnal hyperventilation, compensatory responses and increase of negative intrathoracic pressure, feeling of dyspnoea, fluctuations in blood pressure and consequent sympathetic stimulation ${ }^{3}$. CSA can lead to cardiac arrhythmia, reduced cardiac function and is strongly associated with mortality from sudden cardiac events ${ }^{4}$.

The Loop gain, one of the pathophysiological phenomena which may explain the
Received: August 26, 2019

Accepted: December 3, 2019

Correspondence

Domenico Maurizio Toraldo

via A.C. Casetti 2, 73100 Lecce, Italy

E-mail: d.torald@tin.it

Funding

None.

Conflict of interest

The Authors declare no conflict of interest.

How to cite this article: Toraldo DM, Arigliani M, De Benedetto M. Depressed ventilatory drive for respiratory muscle weakness and chemo-responsiveness as a pathophysiological mechanism of CSA after surgery for obstructive sleep apnoea. Acta Otorhinolaryngol Ital 2020;40:311-312. https://doi. org/10.14639/0392-100X-N0443

() Società Italiana di Otorinolaringoiatria e Chirurgia Cervico-Facciale

\section{cc)(i) $(\ominus$}

This is an open access article distributed in accordance with the CC-BY-NC-ND (Creative Commons Attribution-NonCommercial-NoDerivatives 4.0 International) license. The article can be used by giving appropriate credit and mentioning the license, but only for non-commercial purposes and only in the original version. For further information: https:// creativecommons.org/licenses/by-nc-nd/4.0/deed.en 
OSA, expresses an alteration/exaggeration of the compensatory response to nocturnal hypoventilation. The nocturnal ventilatory disorder, which generates the Loop gain, is achieved through compensatory tachypnoea that reduces the expiratory minute ventilation (alveolar hypoventilation), which, in turn, produces a reduction of $\mathrm{PACO}_{2}$ (alveolar).The magnitude of changes in alveolar $\mathrm{PACO}_{2}$ depends on the responsiveness of the PLANT (the integrated system of lungs, blood and body tissues where $\mathrm{CO}_{2}$ is stored). In addition, changes in the alveolar $\mathrm{PACO}_{2}$ also induce a variation in the sensitivity of the central respiratory drive (ventilatory controller system). The Loop gain expresses the extent of the corrective response in logarithmic terms: the corrective ventilatory disorder will be amplified according to the logarithmic scale and will cause disproportionately large fluctuations.

A large mutability of the ventilatory/receptor response system indicates an unstable system leading to pathological oscillations ${ }^{5}$.

The cyclic Loop gain model, detectable through polygraphic recording performed during HSAT (Home Sleep Apnoea Testing), represents an exclusion criteria for surgical treatment. A high Loop gain indicates an unstable ventilatory system. The mechanisms of the CSA are not known, but various theories have been proposed, such as temporary absence of respiratory effort, and can be seen in a variety of forms in different pathophysiological situations. The reduction of respiratory effort is a consequence of the hypersensitivity of ventilatory responses to changes in the partial $\mathrm{PaCO}_{2} / \mathrm{PaO}_{2}$ pressures detected by carotid peripheral chemoreceptors, i.e. high gain or low gain (overshoot/undershoot). CSA treatment can be explained in terms of positive effects on the Loop gain phenomenon ${ }^{6}$. The following interventions on the CSA are considered therapeutic regarding respiratory mechanisms and ventilatory control: a) treatment with CPAP/Bi-Level or Auto Bi-level improves lung volumes (with consequent hypoventilation improvement) and reduces partial pressure of $\mathrm{PaCO}_{2}$ in peripheral blood (reduction of the ventilatory gain); b) additional therapeutic oxygen therapy has a profound positive impact on CSA, particularly in obese children with respiratory failure and with sleep apnoea, and improves CSA in some patients with heart failure. The increased partial pressure $\mathrm{PaO}_{2}$ reduces chemosensitivity of the peripheral vascular carotid body. Oxygen therapy is expected to increase the gain of the ventilatory response with a consequent decrease in the need for peripheric hypoxaemia compensation; c) respiratory stimulant drugs (e.g. carbon dioxide, rebreathing, acetazolamide and theophylline) work to increase the reduction of the partial pressure of $\mathrm{PaCO}_{2}$, making alveolar $\mathrm{PaCO}_{2}$ less sensitive to changes in ventilation. This drive effect causes a reduction in the difference between alveolar and inspired $\mathrm{PaCO}_{2}$; d) the position of the body during sleep can have a therapeutic impact on CSA. Sleeping sideways or with an overhead lift can improve CSA and can partially lead to a lung volume increase ${ }^{7}$. What happens in post-surgical in OSA patients is a different mechanism than the one previously described. In these patients, central apnoea may be the consequence of a depressive/absent ventilatory effort, with very low Loop gain. In the operated pharyngeal site, the increase in compensatory muscle ventilatory response may be inefficient and produce a low air flow due to poor muscle tone of the airways with increased partial pressure of $\mathrm{PaCO}_{2} \mathrm{mmHg}$ in peripheral blood ${ }^{8}$. This underlines the importance of having an intact or well-functioning carotid chemoreflex control system to obtain a compensatory corrective response ${ }^{9}$. In patients with transient neuromuscular weakness, as may occur in the first post-surgical phase of OSA, central apnoea may be recorded particularly during REM sleep due to a combination of low peripheral chemosensitivity to hypoxaemia, atony or muscle respiratory inefficiency. The absence of effort during these events determines the central apnoea which have been defined "diaphragmatic" to underline the primary role of respiratory muscle weakness in the post-operative phase ${ }^{10}$.

\section{References}

1 Eckert DJ, White DP, Jordan AS, et al. Defining phenotypic causes of obstructive sleep apnea. Identification of novel therapeutic targets. Am J Respir Crit Care Med 2013;188:996-1004. https://doi. org/10.1164/rccm.201303-0448OC

2 MacDonald M, Fang J, Pittman SD, et al. The current prevalence of sleep disordered breathing in congestive heart failure patients treated with beta-blockers. J Clin Sleep Med 2008;4:38-42.

3 Van de Borne P, Oren R, Abouassaly C, et al. Effect of Cheyne-Stokes respiration on muscle sympathetic nerve activity in severe congestive heart failure secondary to ischemic or idiopathic dilated cardiomyopathy. Am J Cardiol 1998;81:432-6. https://doi.org/10.1016/S00029149(97)00936-3

4 Poets CF, Southall DP. Patterns of oxygenation during periodic breathing in preterm infants. Early Hum Dev 1991;26:1-12. https:// doi.org/10.1016/0378-3782(91)90038-5

5 Horner RL, Hughes SW, Malhotra A. State-dependent and reflex drives to the upper airway: basic physiology with clinical implications. J Appl Physiol 2014;116:325-36. https://doi.org/10.1152/japplphysiol.00531.2013

6 Horner RL, Rivera MP, Kozar LF, et al. The ventilatory response to arousal from sleep is not fully explained by differences in $\mathrm{CO}(2)$ levels between sleep and wakefulness. J Physiol 2001;534:881-90. https://doi.org/10.1111/j.1469-7793.2001.00881.x

7 Orr JE, Malhotra A, Sands SA. Pathogenesis of central and complex sleep apnoea. Respirology 2017;22:43-52. https://doi.org/10.1111/resp.12927

8 Sands SA, Edwards BA, Kee K, et al. Loop gain as a means to predict a positive airway pressure suppression of Cheyne-Stokes respiration in patients with heart failure. Am Respir Crit Care Med 2011;184:106775. https://doi.org/10.1164/rccm.201103-0577OC

9 Sands SA, Edwards BA, Kee K, et al. Control theory prediction of resolved Cheyne-Stokes respiration in heart failure. Eur Respir J 2016;48:1351-9. https://doi.org/10.1183/13993003.00615-2016

10 White J, Drinnan M, Smithson A, et al. Respiratory muscle activity and oxygenation during sleep in patients with muscle weakness. Eur Respir J 1995;8:807-14. 